\title{
CFD Analysis of Solar Air Heater Provided with Discrete Inclined Rib Roughness on the Absorber Plate: A Review
}

\author{
Ajay Jain ${ }^{1}$, H. S. Sahu ${ }^{2}$ \\ ${ }^{1}$ Research Scholar, ${ }^{2}$ Assistant Professor, \\ Department Of Mechanical Engineering, Millennium Institute Of Technology Bhopal, Madhya Pradesh, India
}

\begin{abstract}
Heat transfer enhancement is a subject of considerable interest to researchers as it leads to saving in energy and cost. Because of the rapid increase in energy demand in all over The world, both reducing energy lost related with ineffective use and enhancement of energy in the meaning of heat have become an increasingly significance task for design and operation engineers for many system. A 3-dimensional CFD analysis has been carried out to study heat transfer and fluid flow behavior in a rectangular duct of a solar air heater with one roughened wall having discrete inclined rib roughness. The effect of Reynolds number, roughness height, roughness pitch, relative roughness pitch and relative roughness height on the heat transfer coefficient and friction factor have been studied. In order to validate the present numerical model, results have been compared with available experimental results under similar flow conditions.
\end{abstract}

Keywords: CFD Analysis, Absorber plate, Enhancement Factor, Reynolds's No., Nusselt No

\section{INTRODUCTION}

India is blessed with an abundance of sunlight, water and biomass. Vigorous efforts during the past two decades are now bearing fruit as people in all works of life are more aware of the benefits of renewable energy, especially decentralized energy where required in villages and in urban or semi-urban centers. India has the world's largest programmed for renewable energy. Government created the Department of Non-conventional Energy Sources (DNES) in 1982. The phenomenon of Heat transfer Enhancement are Breaking of laminar sub layer, Creation of local wall turbulence and Decrease in the thermal resistance. Solar energy is available freely and an indigenous source of energy provides a clean and pollution free atmosphere. The simplest and the most efficient way to utilize solar energy are to convert it into thermal energy for heating applications by using solar collectors. Solar air heaters, because of their inherent simplicity are cheap and most widely used collector devices. Solar air heaters are being used for many applications at low and moderate temperatures. Some of these are crop drying, timber seasoning, space heating etc.

As early as 4000-3500 BC, the first sailing ships and windmills were developed harnessing wind energy. With the use of hydropower through water mills or irrigation systems, things began to move faster. Fuel wood and dung cakes are even today a major source of energy in rural India. Solar energy is used for drying and heating. With the advent of the Industrial Revolution, the use of energy in the form of fossil fuels began growing as more and more industries were set up. This occurred in stages, from the exploitation of coal deposits to the exploitation of oil and natural gas fields. It has been only half a century since nuclear power began being used as an energy source. In the past century, it became evident that the consumption of non-renewable sources of energy had caused more environmental damage than any other human activity. Electricity generated from fossil fuels such as coal and crude oil has led to high concentrations of harmful gases in the atmosphere. This has in turn led to problems such as ozone depletion and global warming. Vehicular pollution is also a grave problem.

This work basically described the characteristics of the heat transfer and friction is a square duct where various shaped ribs are placed transversely to the main stream direction on one wall. The shape of ribs 
investigated is square, triangular, chamfered and semicircular. The objective of this research are to full fill three aspects i.e., to assess the occurrence of hot spot on the rib roughness wall by investigating the effects of rib shapes on the local heat transfer result for prediction of the flow and heat transfer characteristics in ribbed passages, and to compare the thermal performance of the four type of ribbed duct. The specific objective of the paper are to identify the appropriate governing equation for the problem, develop a computer code to create a computational grid spots on the rib roughened wall by investigating the effect of rib shapes on the local heat transfer and compare the thermal performance of the four type of the ribbed duct finally.

\section{LITERATURE REVIEW:}

There are some papers which have been studied and referred on my work.

\section{Yadav and Bhagoria [Feb. 2015]}

Performed the study of heat transfer and fluid flow processes in an artificially roughened solar air heater by using computational fluid dynamics (CFD), The effects of small diameter of transverse wire rib roughness on heat transfer and fluid flow have been investigated. The Reynolds number, relative roughness pitches (P/e) and relative roughness height (e/D) are chosen as design variables. A twodimensional CFD simulation is performed using the ANSYS FLUENT 12.1 code. The Renormalizationgroup (RNG) k- $\varepsilon$ model is selected as the most appropriate one. Results are validated by comparing with available experimental results. It is apparent that the turbulence created by small diameter of transverse wire ribs result in greater increase in heat transfer over the duct.

\section{Prasad and Saini [2013]}

Developed the relations to, calculate the average friction factor and Stanton- number for artificial roughness of absorber plate by small diameter protrusion wire. They used these relations to compare the effect of height and pitch of roughness element on heat transfer and friction factor with already available experimental data. The friction factor for one side rough duct is determined by assuming that the total shear force in the one side rough duct is approximately equal to combined shear force from three smooth walls in a four sided smooth duct and the shear-force from one rough wall in a four sided rough duct. They used the friction similarity law and heat momentum transfer analogy.

\section{Karwa, SAINI, Solanki [2013]}

Studied and found that the artificial roughness in the form of chamfered ribs groove on the absorber plate result in considerable enhancement of heat transfer. This enhancement is, however, accompanied by a substantial increase in the friction factor. It is therefore desirable to select the roughness geometry such that the heat transfer coefficient is maximized while keeping the friction losses at the minimum possible value. Considering the heat transfer and friction characteristics can fulfill this requirement the collector simultaneously.

\section{Lanjewar and Bhagoriya [2012]}

Performed the study of heat transfer and fluid flow processes in an artificially roughened solar air heater by using computational fluid dynamics (CFD), The effects of small diameter of transverse wire rib roughness on heat transfer and fluid flow have been investigated. The Reynolds number, relative roughness pitches $(\mathrm{P} / \mathrm{E})$ and relative roughness height (e/D) are chosen as design variables. A twodimensional CFD simulation is performed using the ANSYS FLUENT 12.1 code. The Renormalizationgroup (RNG) key model is selected as the most appropriate one. Results are validated by comparing with available experimental results.

\section{Prasad and Mullick [2011]}

Developed a protruding wires on the underside of the absorber plate of an unglazed solar air heater for cereal grains drying to improve the heat transfer characteristics and hence the plate efficiency factor. Investigate on solar air heater with protruding wires in underside of the absorber plate. They found improvement of $9 \%$ (from $63 \%$ to $72 \%$ ) in plate efficiency (FP) for Reynolds number of 40,000. The plate efficiency is $44.5 \%$ higher in cross corrugated sheet with protruding wire than plane galvanized iron sheet.

\section{Saini and Verma [2010]}

Conducted an experimental investigation on fluid flow and heat transfer characteristics of solar air heater duct having dimple-shaped artificial roughness, Authors found maximum value of Nusselt number corresponds to relative roughness height (e/D) of 0.0379 and relative roughness pitch (P/E) of 10 . Authors also found minimum value of friction factor 
correspond to relative roughness height (e/D) of 0.0289 and relative pitch $(\mathrm{P} / \mathrm{E})$ of 10 .

\section{Verma and Prasad [2008]}

Developed of a heat transfer in the solar air heater ducts can be achieved by several means like using baffles, fins, ribs and groves. Until now, various attempts have been made to investigate the effects of these geometries on the enhancement of the heat transfer rate; however it is achieved at the cost of the increase in the pressure drop across the surfaces on which the scene elements are mounted. This paper is an attempt to summarize and conclude the investigation involving the use of small height elements and surface protrusions on absorber plate and channel walls as artificial roughness elements of various geometries and its effect on heat transfer and friction factor through experiments. It also summarizes the various correlations which have been developed for Nusselt number $(\mathrm{Nu})$ and Friction factor (f) and reported in the previous investigations. The comparative study has been done to understand the results of these investigations for solar air heaters with different roughness elements on its absorber surface.

\section{Bopche and Tandale [2007]}

Performed for the thermo-hydraulic performance of solar air heaters with inverted U-shaped ribs on the absorber plate, They concluded that their roughness element is efficient in heat transfer even at lower Reynolds number (Re-5000). They further concluded that the turbulence is created only in the viscous sublayer resulting in higher thermo-hydraulic performance than smooth solar air heaters.

\section{Karmare and Tikekar [2006]}

Performed CFD investigation of fluid flow and heat transfer in a solar air heater duct with metal grit ribs as roughness elements on the absorber plate, Commercial CFD code FLUENT 6.2.16 was used as a solver. Standard k-e turbulence model was used to simulate turbulent airflow through artificially roughened solar air heater. Circular, triangular and square shape rib grits with the angle of attack of $54^{\circ}$, $56^{\circ}, 58^{\circ}, 60^{\circ}$ and $62^{\circ}$ were tested for the same Reynolds number. Authors reported that amongst the different shapes and orientations analyzed, the absorber plate of square cross-section rib with $58^{0}$ angle of attack gave the best results. The percentage increase in the heat transfer for $58^{0}$ rib inclination plate over smooth plate was found to be about $30 \%$.
In order to validate CFD results, experimental investigations were carried out in the laboratory.

\section{Gandhi and Singh [2005]}

Performed a numerical investigation to investigate the effect of artificial surface roughness on flow through a rectangular duct having bottom wall roughened with repeated transverse ribs of wedge shaped crosssection, Two dimensional numerical modeling of the duct flow using FLUENT showed reasonably good agreement with the experimental observations except for the friction factor. Numerical results obtained by commercial computational fluid dynamics (CFD) code FLUENT were compared with the experimental results.

\section{METHOD AND SOFTWARE USED \\ Computational Fluid Dynamics:}

Computational fluid dynamics (CFD) is a computer-based simulation method for analyzing fluid flow, heat transfer, and related phenomena such as chemical reactions. This project uses CFD for analysis of flow and heat transfer. Some examples of application areas are: aerodynamic lift and drag (i.e. airplanes or windmill wings), power plant combustion, chemical processes, heating/ventilation, and even biomedical engineering (simulating blood flow through arteries and veins). CFD analyses carried out in the various industries are used in $R \& D$ and manufacture of aircraft, combustion engines, as well as many other industrial products. It can be advantageous to use CFD over traditional experimental-based analyses, since experiments have a cost directly proportional to the number of configurations desired for testing, unlike with CFD, where large amounts of results can be produced at practically no added expense. In this way, parametric studies to optimize equipment are very inexpensive with CFD when compared to experiments.

\section{Flow analysis and CAD MODELLING}

After studying the basic steps in CFD to be followed to analysis the flow inside a duct. Now we can start the analysis of the solar air heater with actual data .following three steps are required to run the simulation- Pre processing: 1-CAD modeling, 2Meshing, 3-type of solver, 4- physical model, 5material property, 6-boundary condition.

\section{CONCLUSIONS}

A 3-dimensional CFD analysis has been carried out to study heat transfer and fluid flow behavior in a 
rectangular duct of a solar air heater with one roughened wall having discrete inclined rib roughness. The effect of Reynolds number, roughness height, roughness pitch, relative roughness pitch and relative roughness height on the heat transfer coefficient and friction factor have been studied. In order to validate the present numerical model, results have been compared with available experimental results under similar flow conditions. CFD Investigation has been carried out in medium Reynolds number flow (Re 1/43800e18, 000).

\section{REFERENCES}

1. Yadav A.S, Bhagoria J.L, A CFD based heat transfer and fluid flow analysis of a solar air heater provided with circular transverse wire rib roughness on the absorber plate, Energy 55 (2015) 1127-1142

2. Prasad K and Saini J.S, An experimental investigation in transverse ribs on the absorber plate by assuming that the total shear force, Heat and mass transfer 40 976-993 (2013).

3. Karwa R, Solanki S.C, Saini S.C, Thermohydraulic performance of solar air heaters having integral chamfered rib roughness on absorber plates 26 (2001) 161-176(2013)

4. Lanjewar A, Bhagoria J.L, Sarvaiya R.M "Augmentation of heat transfer coefficient by using $90^{\circ}$ broken transverse ribs on absorber plate of solar air heater". Renewable Energy 36\45314541. (2012).

5. Prasad K, Mullick S.C, Heat transfer characteristics of a solar air heater used for drying purposes, Appl. Energy 13 (2) (2011) 83-93.

6. Saini R.P, Verma J, An experimental setup on the fluid flow and heat transfer of solar air heater duct having dimple -shaped artificial roughness, Energy 33 (2010) 1277-1287.

7. Verma S.K, Prasad B.N, Investigation for the optimal thermo-hydraulic performance of artificially roughened solar air heaters, Renewable Energy 20 (2008) 19-36.

8. Bopche S.B, Tandale M.S, Experimental investigations on heat transfer and frictional characteristics of a tabulator roughened solar air heater duct, Int. J. Heat Mass Transfer 52 (2007) 2834-2848.

9. Karmare S.V, Tikekar A.N. Heat transfer and friction factor correlation for artificially roughened duct with metal grit ribs, Int. J. Heat Mass Transfer 50 (2007) 4342-4351.

10. Yadav A.S, Bhagoria J.L, A numerical investigation of turbulent flows through an artificially roughened solar air heater, Numer. Heat Transfer A, 2006

11. Yadav A.S, Bhagoria J.L, Heat transfer and fluid flow analysis of an artificially roughened solar air heater: a CFD based investigation, Front. Energy, 2005.

12. Singh S, Chander S, Saini J.S, Heat transfer and friction factor correlations of solar air heater ducts artificially roughened with discrete V-down ribs, Energy 36 (2004) 5053-5064.

13. Yadav A.S, Bhagoria J.L, A CFD based thermohydraulic performance analysis of an artificially roughened solar air heater having equilateral triangular sectioned rib roughness on the absorber plate. Heat and mass transfer 70 1016-1039 (2003).

14. M.M. Sahu, J.L. Bhagoria "Augmentation of heat transfer coefficient by using $90^{\circ}$ broken transverse ribs on absorber plate of solar air heater". Renewable Energy (2002).

15. Hans V.S, Saini R.P, Saini J.S, Heat transfer and friction factor correlations for a solar air heater duct roughened artificially with multiple V-ribs, Sol. Energy 84 (2001) 898-911. 